NEW NIST PUBLICATION

December 1989

\title{
POTENTIAL METHODS FOR MEASURING AND DETECTING LEAD IN EXISTING PAINT FILMS: A LITERATURE REVIEW
}

W. Eric Byrd

Mary E. McKnight

U.S. DEPARTMENT OF COMMERCE National Institute of Standards and Tochnology Center for Bullding Technology Bullding Materials Division Galthersburg, MD 20899

U.S. DEPARTMENT OF COMMERCE Robert A. Mosbacher, Secretary Lee Mercer, Deputy Under Secretary for Technology

NATIONAL INSTTUUTE OF STANDARDS AND TECHNOLOGY

Raymond G. Kammer, Acting Director 



\section{POTENTIAL METHODS FOR MEASURING AND DETECTING LEAD IN EXISTING PAINT FILMS: A LITERATURE REVIEW}

W. Eric Byrd

Mary E. McKnight

U.S. DEPARTMENT OF COMMERCE Natlonal Instltute of Standards and Technology Center for Bullding Technology Bullding Materlals Division Galthersburg, MD 20899

January 1990

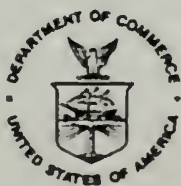

U.S. DEPARTMENT OF COMMERCE Robert A. Mosbacher, Secretary

Lee Mercer, Deputy Under Secretary for Technology

NATIONAL INSTITUTE OF STANDARDS AND TECHNOLOGY

Raymond G. Kammer, Acting Director 

POTENTIAL METHODS FOR MEASURING AND DETECTING LEAD IN EXISTING PAINT FILMS: A LITERATURE REVIEW

\begin{abstract}
Recent legislation required the U.S. Department of Housing and Urban Development (HUD) to establish procedures to eliminate, as far as practicable, the hazards of lead-based paint poisoning in any existing HUD-controlled housing. Thus, HUD promulgated a regulation which requires abatement to eliminate lead-based paint poisoning hazards in housing in which the concentration of lead in paint equals or exceeds $1 \mathrm{mg} / \mathrm{cm}^{2}$. The legislation also required HUD to review test methods for measuring lead in paint. The National Institute of Standards and Technology (NIST) was given this task. That review is the subject of this report. Test methods were evaluated based on the following criteria: 1 ) safety, 2) reliability, 3) accuracy, 4) precision, 5) detection limit, 6) ease of use, and 7) technical skill required to make a measurement, 8) nondestructive, and 9) cost of an analysis. Methods were separated into two categories: 1) field test methods and 2) laboratory test methods. The laboratory test methods were also separated by whether the sample needed to be in solution or could be analyzed as a solid. None of the potential test methods met all of the desired criteria.
\end{abstract}

Key words: analysis; lead; literature review; paint; $x-r a y$ fluorescence; flame atomic absorption; spot test; inductively coupled plasma; neutron activation analysis; voltammetry; mass spectrometry; ion selective electrodes 


\section{TABLE OF CONTENTS}

1. INTRODUCTION . . . . . . . . . . . . . . . . 1

2. FIELD TEST METHODS ................... 3 2.1 Portable X-Ray Fluorescence . . . . . . . . 3 2.2 Spot Tests................ 8

3. LABORATORY TEST METHODS ............... . 13

3.1 Flame Atomic Absorption spectroscopy . . . . . 13

3.2 Inductively Coupled Plasma . . . . . . . . . 17

3.3 Voltammetry . . . . . . . . . . . . . . 19

3.4 Laboratory X-Ray Fluorescence . . . . . . . 21

3.5 Neutron Activation Analysis . . . . . . . 24

3.6 Mass Spectrometry .. . . . . . . . . 26

3.7 Ion Selective Electrodes . . . . . . . . 27

4. CONCLUSIONS . . . . . . . . . . . . . . . 27

5. REFERENCES . . . . . . . . . . . . . . 29 


\section{LIST OF FIGURES}

Figure 1. Typical configuration of a portable x-ray fluorescence instrument.

Figure 2. Graph of $95 \%$ confidence interval versus the number of readings.

Figure 3. Hypothetical Distribution of results of measurement process when a) limit for bias is zero and b) when limit for bias is $\Delta$. Solid double lines correspond to 95\% confidence interval for measurement process with limit for bias of $\Delta$. Dotted lines correspond to $95 \%$ confidence interval when bias is zero.

Figure 4. Effect of battery life on the response of a portable $x-$ ray fluorescence instrument.

Figure 5. Schematic of Flame Atomic Absorption Spectrophotometer.

Figure 6. Inductively Coupled Plasma source diagram

Figure 7. Schematic diagram of the polarographic technique

a) Side view

b) top view 



\section{INTRODUCTION}

An amendment to the Lead-Based Poisoning Prevention Act by Section 566 of the Housing and Community Development Act of 1987 (Public Law 100-242, approved February 5, 1988), requires the U.S. Department of Housing and Urban Development (HUD) to "establish procedures to eliminate as far as practicable the hazards of lead-based paint poisoning with respect to any existing housing which may present such hazards and which is covered by an application for mortgage insurance or housing assistance payments under a program administered by the Secretary." In response to this legislation, HUD promulgated a regulation which requires abatement to eliminate the lead-based paint poisoning hazards in housing in which the concentration of lead in paint equals or exceeds $1 \mathrm{mg} / \mathrm{cm}^{2}$ [1]. In addition, the legislation required HUD to periodically review and reduce the level below $1 \mathrm{mg} / \mathrm{cm}^{2}$ to the extent that reliable technology makes feasible the detection of a lower level and medical evidence supports the imposition of a lower level. Currently, the maximum allowable lead in consumer paint is $0.06 \%$ by mass of total solids (600 parts per million) [2].

The National Institute of Standards and Technology (NIST, formerly NBS) has been asked by the U.S. Department of Housing and Urban Development (HUD) to develop recommendations, based upon current state-of-the-art information and upon laboratory and 
field data, on methods for use in the detection and measurement of lead in dry paint films. An essential step in decision-making regarding abatement of lead-containing paints is to determine if lead is present and, if so, how much is present. There are many procedures for the determination of lead. These methods may or may not be suitable for the determination of total lead in aged paint films. The first phase of this process is to identify potential methods. This report is a result of a literature survey on potential methods of measuring lead in lead-based paint films. A later report will make final recommendations.

A review of the literature revealed both field test methods and laboratory test methods for the measurement of the lead content of materials. Each of the methods will be discussed, where relevant, using the following criteria as a guide:

1. Safety: Does the method require a high degree of operator training or operator awareness to be conducted in a safe manner?

2. Reliability: Is the instrument rugged enough for a field test method?

3. Accuracy: The agreement between the observed value for an analysis and its true value

4. Precision: The ability to consistently duplicate the observed value when an analysis is repeated

5. Detection limit: Does the method have a detection limit capable of measuring the legal limit?

6. Ease of use: Time required to make a measurement

7. Technical: Skill level needed to perform a measurement

8. Nondestructive: Does the method damage the surface to be measured?

9. Cost: Cost per measurement - including sample acquisition and laboratory analysis, if applicable. 
2. FIELD TEST METHODS

2.1 Portable X-Ray Fluorescence

$x$-ray fluorescence is the result of a two step process. Step one is when a photon strikes an electron in an atom with sufficient energy for the electron to be ejected from the atom. Step two is when an electron from a lower energy state transfers to the site of the ejected electron (which was in a higher energy state) and in the process emits a x-ray photon of an energy characteristic for each element.

Considerable interest was shown in the 1970 's for in-situ measurement of lead in paint with the use of portable $x-r a y$ fluorescence (PXRF) instrumentation. Several studies were done in the United States, Canada, and England that used both commercially available PXRF instruments as well as prototype PXRF instrumentation $[3-12]$.

PXRF instruments referenced in the literature for measuring lead in paint films use either 10-25 millicurie cobalt-57 or 5 millicurie cadmium-109 as an excitation source [7]. A typical configuration of a PXRF is shown in Figure 1 [13]. Shielding of the source keeps operator radiation exposure to a minimum. The instruments have a shutter-type mechanism that automatically isolates the source when the instrument is not in use. When 
properly used these instruments are designed to provide a high degree of safety.

Laurer et. al. [4] measured operational doses of radiation at four different distances from a prototype instrument that used a 5 millicurie cadmium-109 excitation source: 1) $150 \mathrm{~mm}$ in front of the uncapped source, $25 \mathrm{millirem} /$ hour; 2) $150 \mathrm{~mm}$ in front of the capped source, background level; 3) $300 \mathrm{~mm}$ from the wall surface with the instrument in the operating position against the wall surface, $0.03 \mathrm{millirem} / \mathrm{hour}$; and 4 ) at the surface of a hollow, wood-lathed plastered wall directly opposite the source i.e., transmission through a wall with a relatively small degree of attenuation, $0.25 \mathrm{millirem} / \mathrm{hour}$. This compares with the current allowable limit of $5 \mathrm{millirem} /$ year [14].

Currently, the excitation source used in two commercial lead specific PXRF instruments is 10 millicuries of cobalt-57. When the shutter of these instruments is open, an exposure at the surface of the beam port can be as high as $1200 \mathrm{millirem} / \mathrm{hour}$. Under normal operating conditions, the maximum exposure at the beam port of one of these PXRF instruments is between 10-15 millirem/hour [15].

For a field test instrument to be reliable, it must be rugged enough to withstand the effects of day to day handling. The instrument must also accommodate wide (by laboratory standards) 
temperature variations. PXRF instruments that use sodium iodide as the detector element may be unable to adjust to temperature changes as small as $10^{\circ} \mathrm{C} /$ hour [13], hence, time must be allotted for these instruments to come to thermal equilibrium prior to making measurements.

In the measurement of lead content between 1.0 and $6.6 \mathrm{mg} / \mathrm{cm}^{2}$, errors of 30-50\% are reportedly not uncommon for data acquired under conditions where the paint films were applied to flat panels of known substrate type [7]. Because conditions in the field will not be as well characterized, larger errors are expected to occur. The relative error may decrease for the measurement of higher lead levels [7].

Precision is normally presented in terms of the standard deviation of the measurement process. It is a measure of the random error associated with the measurement. Bias or systematic error, usually considered separately from precision, causes all the results to be shifted away from the true value. Precision and bias, together, determine the confidence that can be placed in the measurement, i.e., the confidence interval or the detection limit.

To illustrate, when experimental results are normally distributed and the standard deviation of the population is known, for a $95 \%$ confidence limit, only 5 of every 100 results would be expected 
to vary from the mean of the measurements by more than plus or minus twice the standard deviation $(2 \sigma)$. When the mean of several measurements is used to estimate the "true" or population mean, the uncertainty in the measurements is decreased by a factor depending upon the number of replicates. This is illustrated in Figure 2. Note that the uncertainty in the measurement results associated with random error decreases rapidly as $n$ increased from 1 to 5 , but then decreases much more slowly. However, when a blank signal is subtracted from a gross signal or when a calibration curve is used to obtain an experimental result, the uncertainty in the result is increased $[16,17]$

Bias or systematic error causes the entire distribution to be shifted away from the "true" one, as illustrated in Figure 3 , decreasing the confidence that can be placed in the measurement. For PXRF measurements, bias could be attributed to such factors as matrix effect, inhomogeneity of the painted surface, and effects of differing substrates [8].

Detection limit has been defined in a number of ways. Currie [16] identified four definitions for detection limits related to current U.S. regulatory practice. Detection limit is often defined in terms of a simple multiple of the standard deviation of the measurement process. Statistical theory and hypothesis testing, which currently is preferred by many analytical 
chemists, provides a procedure for defining detection limit that incorporates risks for both a false positive and a false negative decision and also provides for incorporating the limits for bias into the detection limit. This definition with respect to PXRF measurements was discussed in a previous report [18]. Since this definition was not used in much of the previous work and several different definitions of detection limit were used, the precision, limit for bias (if known), and the definition for the detection limit used in a particular study will be included in discussions of reported PXRF data in this report.

Rasberry [7] arbitrarily defined the detection limit as twice the standard deviation for samples near the detection limit. He reported detection limits from $0.9 \mathrm{mg} / \mathrm{cm}^{2}$ to $0.3 \mathrm{mg} / \mathrm{cm}^{2}$ for several PXRF instruments. The lower reading was for a prototype instrument having a lithium-drifted germanium detector.

PXRF instruments are relatively easy to use in lead-based paint analysis in the field. With semi-skilled personnel, in-situ measurements can be made quickly ( 2 minutes/reading) and nondestructively.

Power to operate lead specific PXRF instruments is supplied by rechargeable batteries. These have a limited lifetime (usually about 5 hours). As the batteries discharge, the lower energy may have an effect on instrument response [8]. Figure 4 shows the 
effect of battery charge on instrument response for one instrument. The battery was fully charged and then discharged in one hour steps. The plot labeled 1.5 hours is the average of the 1 and 2 hour discharge times [8].

\subsection{Spot Tests}

Chemical spot tests (in particular, sodium sulfide) have been used for a number of years as a quick method for lead-based paint screening [18]. All spot tests used in lead detection work by a process in which lead is chemically converted to a compound which results in a color change. To some degree, the amount of color change is proportional to the amount of lead in the sample. Spot tests generally are very subjective in that the degree of color change is compared with a visual standard to quantify the lead amount. Additional sources of error may include those due to: 1) lead bound in a polymer matrix and unable to react; 2 ) lead in an improper oxidation state or having inadequate solubility for reaction with the spot test reagent and; 3 ) presence of other elements which cause the same color change as lead [15]. Several different spot tests for lead in paint were identified and although several of these spot tests should be considered as laboratory methods, they will also be discussed in this section.

The spot test most commonly used for in-situ detection of lead in paint is the sodium sulfide test. In this test, a sodium sulfide 
solution is placed on the paint and available lead ions are converted to lead sulfide (an insoluble black precipitate), through the following reaction [19]:

$$
\mathrm{Pb}^{++}+\mathrm{Na}_{2} \mathrm{~S} \longrightarrow \mathrm{PbS} \downarrow+2 \mathrm{Na}^{+}
$$

The gradation from light gray to black is proportional to the amount of lead in the paint. Lead concentration can be measured semi-quantitatively in the range of $0.5 \%$ to $25 \%$ lead if lead is present as $\mathrm{Pb}^{++}$.

Fiegl and Anger [20] list several other spot tests for lead. These include: 1 ) reaction with oxidizing agents to form lead dioxide; 2) reaction with sodium rhodizonate; and 3 ) reaction with dithizone. All of these tests are described for the case in which the lead compound is in solution. Therefore, these tests may not be applicable as field tests.

The American Society for Testing and Materials (ASTM) Standard Method D 3618-85a, Standard Test Method for Detection of Lead in Paint and Dried Paint Films [21] is a spot test in which lead in solution is oxidized to lead peroxide with bromine water and then treated with "tetrabase reagent" (4,4'-Methylenebis $(\mathrm{N}, \mathrm{N}-$ dimethylaniline)) to yield a blue quinoidal salt. This method can detect $0.5 \%$ of lead in paint solids, but can barely detect $0.4 \%$ presence of lead. As with the methods listed in Fiegl and Anger, this method requires that the lead compound be in solution and is therefore difficult to use in the field. 
There may be potential safety problems associated with various spot tests. The sodium sulfide spot test uses sodium sulfide which is an alkaline compound which should not be handled with bare hands [22]. The spot test in which lead dioxide is formed (Fiegl and Anger) uses an alkali solution, ammonia, and acetic acid [20]. All of these chemicals can cause irritations if they come in contact with the skin [22]. The dithizone spot test uses carbon tetrachloride (listed as a carcinogen by the EPA) [22] as a solvent for the dithizone. ASTM D 3618-85a [21] uses acetic acid, ammonium hydroxide, sodium hydroxide and nitric acid. Again, all of these chemicals can cause skin irritations [22]. Furthermore, any test that requires that the sample be in solution will use an acid digestion step containing nitric acid, a strong oxidant and corrosive agent that can cause severe burns if it contacts the skin.

The major reliability problem with spot tests involves deterioration of the chemicals. If a chemical is used that has lost its effectiveness, it may lead to a conclusion that less lead is present than is actually present. Sodium sulfide solution exposed to air degrades over a period of time to an inert solution of sodium hydroxide [22]. Sodium rhodizonate solution is unstable even when refrigerated and fresh solutions must be prepared every day. Dithizone solutions in carbon tetrachloride are not stable and must be stored under an aqueous 
layer saturated with sulfur dioxide $\left(\mathrm{SO}_{2}\right)[22]$. The chemicals used in ASTM D 3618-85a are more stable than those used in the other tests, but may lose their effectiveness over a period of time.

The only data available regarding accuracy and precision are from ASTM D 3618-85a. In a round-robin test with eight labs, all correctly identified lead levels above $0.5 \%$ lead (positive) and less than $0.5 \%$ lead (negative) with only one laboratory reporting a single result as questionable [21]. Although no data is available for the other spot tests, a reasonable assumption is that there will be a high degree of operator bias in these tests. Different analysts will interpret the color changes in different ways giving a large amount of bias in the accuracy and precision data.

Detection limits for the sodium sulfide spot test have been stated as low as $0.8 \%$ lead [19]. The detection limit (defined as the amount that is detectable in $0.05 \mathrm{ml}$ of test solution) of the spot tests referenced in Fiegl and Anger [20]: range from $1 \mu \mathrm{g}$ for formation of lead dioxide, $0.1 \mu \mathrm{g}$ for sodium rhodizonate, and $0.04 \mu \mathrm{g}$ for dithizone. ASTM D 3618-85a [21] has a detection limit of $0.5 \%$ lead, but can barely detect lead at a $0.4 \%$ lead level.

Ease of use can be a problem in all of these tests. The simplest 
of these tests is the sodium sulfide spot test. It requires that the lead be accessible to the sodium sulfide solution. This means that any non-lead based paint layer either be removed or be scribed in such a way that the sodium sulfide solution can reach the lead-based paint layer so that lead sulfide can be detected by the analyst [19]. The other tests require that the lead compound be in solution. This requires a number of additional steps before the sample can be analyzed. Dry ashing of a paint sample requires 1 hour in a $500^{\circ} \mathrm{C}$ furnace following by acid digestion of the ash [21]. All of these additional steps increase the complexity of the analysis.

The technical skills required to perform these spot tests involve: 1) preparing chemical solutions of a relatively high degree of accuracy, 2) proper handling of the test chemicals, and 3) determining small color changes in a sample. The analyst will need to have some fundamental knowledge of general and analytical chemistry procedures.

None of these spot tests can be considered to be nondestructive. The least destructive test (sodium sulfide) requires at a minimum, that the surface be scribed down to the substrate. The other tests require that a sample be removed for analysis. 


\section{LABORATORY TEST METHODS}

Many test methods can be used in the laboratory for the analysis of lead. A major practical difference between the laboratory methods and the field methods is that in most laboratory methods, the lead sample must be in solution. For a lead-based paint sample, this requires dissolution of the paint matrix by either wet ashing or dry ashing of the sample and then an additional step of acid digestion. The requirement that the sample be in solution adds a minimum of one hour to the analysis time for each sample. Laboratory methods which use a solid sample may greatly simplify the analysis

\subsection{Flame Atomic Absorption Spectroscopy}

Absorption spectroscopy is based upon absorption of electromagnetic radiation by atoms or ions. In lead analysis using flame atomic absorption spectroscopy (FAAS), a solution containing the lead ions in solution from the lead-based paint sample is aspirated into the flame and the lead atoms are atomized to a gaseous state. The hot gaseous lead atoms then absorb radiation that is characteristic of transitions from the ground state to upper level excited states.

The instrument used in flame atomic absorption spectroscopy consists of four basic components (Figure 5): 1) a hollow cathode 
lamp that produces electromagnetic radiation of very discreet lines, 2) a flame to aspirate the liquid sample and convert the Iiquid sample to gaseous atoms, 3) a monochromator to separate the absorption peaks of the excited atom, and 4) a detector and electronics to measure the energy level and give a reading [23].

FAAS is a well documented technique that has been used for a number of years in lead-based paint analysis $[24-30]$. A reflection of this is that there are standard methods for leadbased paint analysis using FAAS.

A standard method for lead analysis in paint is ASTM D 3335-85a, Standard Test Method for Low Concentrations of Lead, Cadmium, and Cobalt in Paint by Atomic Absorption spectroscopy [25]. This method requires dry ashing of the sample at 475 to $500^{\circ} \mathrm{C}$, dissolving the ash in nitric acid, and filtering the acid solution. The solution is then analyzed using FAAS at a wavelength of $283.3 \mathrm{~nm}$.

There are two major safety concerns in FAAS. The first concern is that the sample must be in solution to be analyzed. This involves the use of nitric acid as the dissolving chemical. Although nitric acid is routinely used in analytical laboratory procedures, it is also a strong corrosive agent which can cause severe burns if it comes into contact with the skin [22]. The second concern is that the fuel and oxidant source for the flame 
is usually acetylene and oxygen or air [23]. Acetylene mixed with as little as $3 \%$ air is explosive [22]. This problem can be minimized if the instrument is properly maintained and vented.

FAAS is a standard analytical instrument with relatively few moving parts. If the instrument is maintained and operated correctly, it should be an extremely reliable instrumental technique. Maintenance consists of 1) keeping the optical path clean, 2) maintaining the fuel and oxidant supply, and 3) keeping the flame burner clean to minimize soot and contaminants. The most unreliable component is the hollow cathode lamp, which is under a slight pressure of an inert gas. Over a period of time this gas escapes and the lamp becomes inoperative. This should not be a major problem as a hollow cathode lamp can be replaced in a matter of minutes.

Very little data exists on accuracy and precision in lead-based paint analysis using FAAS. Hausknecht et. al. [24] reported lead losses of more than $90 \%$ when paint samples are ashed at $500^{\circ} \mathrm{C}$, but these results were based upon a small number of samples. Porter [30] also reported significant lead losses (1/2 to $2 / 3)$ using the dry ashing technique. Again this assumption is based upon a small number of samples. Bock [31] concluded that in most cases, significant lead loss will not occur in samples heated at temperatures from 450 to $500^{\circ} \mathrm{C}$ if large amounts of chloride are not present. Obviously, if there is significant lead loss using 
the dry ashing technique, this will cause gross errors in accuracy and precision.

Round robin test data is available for ASTM D 3335-85a. In this test the standard deviation of the difference between duplicate determinations was determined to be $4 \%$, and for a $95 \%$ confidence level two determinations should be considered suspect if they differ by more than $11 \%$. Unlike Hausknecht and Porter, no significant lead losses were observed using the dry ashing technique [32].

ASTM D 3335-85a has a detection limit for lead of between 0.01 and $5 \%$ lead in paint. Paint samples that contain greater amounts of lead would require dilution [25]. Kubota et. al. [26], using a wire-loop method in FAAS, reported a detection limit of 0.1 to $1 \mu \mathrm{g} / 10 \mu \mathrm{l}$ of solution ( $1 \%$ to $10 \%$ ). This method has the advantage of only requiring 10 microliter of sample for an analysis. Using standard operating conditions, lead amounts of $0.5 \mu \mathrm{g} / \mathrm{ml}$ can be measured at $1 \%$ absorbance and with a modification of the method $0.001 \mu \mathrm{g} / \mathrm{ml}$ of lead can be detected [33].

FAAS is a fast and convenient method to measure lead in paint after the lead is in solution. An analysis can take as little as five minutes. The time consuming step is the dry ashing and acid digestion of the sample. Another disadvantage of FAAS is that it 
requires a relatively large sample. ASTM D 3335-85a uses 1-2 grams of dried paint film in an analysis [25]. FAAS also requires a relatively high degree of operator training to operate the instrumentation. A further disadvantage of FAAS is that a sample must be taken to the laboratory for analysis and this means that the method is destructive.

\subsection{Inductively Coupled Plasma}

Inductively coupled plasma (ICP) is an emission technique in which a plasma source is used to excite the ground state atoms to higher energy orbitals [23]. At room temperature essentially all the atoms are in the ground state. The high-energy plasma source excites a large percentage of the atoms into higher energy states. The lifetime of the excited atom is brief and the return to the ground state is accompanied by the emission of a photon of radiation.

The basic ICP instrumentation is very similar to an atomic absorption spectrophotometer. The major difference is that the flame source of FAAS is replaced by a plasma source (Figure 6). This source consists of three concentric quartz tubes through which argon flows at a rate of between 11 and $17 \mathrm{~L} / \mathrm{min}$. surrounding the top of this tube is a water-cooled induction coil that is powered by a radio-frequency generator capable of producing $2 \mathrm{~kW}$ of energy at about $27 \mathrm{MHz}$. Ionization of the 
flowing argon is initiated by a spark from a Telsa coil. The resulting ions and their associated electrons interact with the fluctuating magnetic field produced by the induction coil. This interaction forces the ions and electrons to flow in a closed annular path and ohmic heating results from their resistance to this movement. This plasma source achieves temperatures as great as $10,000^{\circ} \mathrm{K}$ and requires water-cooling of the quartz tubes to prevent them from melting.

Any emission spectroscopic technique that utilizes a plasma source instead of a flame source has several advantages. Among these is lower interelement interferences, which is a direct result of their higher source temperatures. Because the plasma source background is made of inert argon, there is little spectral interference from the source. Also, because good spectra can be resolved from a single set of excitation conditions, multielement analysis can be done simultaneously.

There are three primary disadvantages to using ICP as an analysis technique [23]. The first is that the sample must be in solution to be analyzed. This requires either an acid digestion or a dry ashing sample preparation. The second disadvantage is that the instrument is relatively expensive. Since ICP is a multielement technique, it is probably a more powerful analysis tool than is needed for a single element determination. The third disadvantage is that the plasma source requires 11-17 liters of 
argon per minute. This requirement necessitates the use of liquid argon, which is allowed to vaporize to gaseous argon, to meet the high flow rate required for the plasma source.

\subsection{Voltammetry}

Voltammetry consists of a group of electroanalytical methods in which information about the analyte is obtained from the measurement of current as a function of applied potential obtained under conditions that encourage polarization of the indicator or working electrode. The method dates from the 1920's with the discovery of polarography by the czechoslovakian chemist Jaroslav Heyrovsky [23]. There are many different methods of voltammetry and these include: classic or linear-scan polarography, current-sampled polarography, norma-pulse polarography, differential-pulse polarography, fast linear-sweep polarography, cyclic voltammetry, alternating current polarography, and stripping voltammetry. The analytical technique is similar in all of these methods, with the applied potential being the major difference between these techniques.

Instrumentation for voltammetry is relatively simple (Figure 7) [23]. The instrument consists of three electrodes 1) a mercury dropping electrode to transfer the potential 2) a calomel reference electrode and 3) a counter electrode. The counter 
electrode, made of an inert conducting material, provides an electrode surface to carry part of the current and minimizes the size of the reference electrode. These electrodes are mounted into a heavy-walled glass container which has an inlet so that nitrogen can be flushed through the sample solution or over the sample surface. The final component is a power source to provide the potential. This can vary from a simple voltage divider to a computer controlled power source providing varying differential voltages.

Lai and Fung [34] performed a comparison study of lead determination using differential-pulse anodic-stripping voltammetry (DPASV) and flame atomic absorption spectrophotometry. Detection limits for DPASV were found to be in the nanogram region. The measured lead contents were in reasonable agreement with FAAS with the added advantage that DPASV required between $0.27-20.43 \mathrm{mg}$ of sample while FAAS required 50-100 $\mathrm{mg}$ of sample. In this comparison a semi-micro balance with an accuracy of $\pm 0.01 \mathrm{mg}$ was used. The accuracy of the result obtained when using the DPASV technique was reported to be greater than the weighing accuracy.

Voltammetry as an analytical technique has several inherent advantages. The first of these is that the equipment is relatively simple and, therefore, can be relatively inexpensive to purchase. Instrumentation prices can be as low as a few 
hundred dollars to as much as several thousand dollars based primarily on the complexity of the polarization source [23]. The second advantage of voltammetry is that an analysis can be performed on small samples (as little as $0.27 \mathrm{mg}$ ). The third advantage is a low detection limit in the nanogram region [34].

Voltammetry also has several disadvantages as an analytical technique for lead-based paint analysis. The first disadvantage is that the sample must be in solution to perform a voltammetric analysis. This requires either acid digestion or wet ashing of the sample. The second disadvantage is that a voltammetric analysis takes a relatively long time compared to other techniques such as FAAS. An analysis can take as long as 10-15 minutes after the sample is put into solution. The third disadvantage of voltammetry is that virtually all instruments use a mercury drop electrode as the polarization electrode. This requires a reservoir of mercury [23], which is a hazardous material [22].

\subsection{Laboratory X-Ray Fluorescence}

Laboratory $x$-ray fluorescence (LXRF) employs the same operating principle as that used in lead specific portable $x$-ray fluorescence instruments. The primary difference between IXRF and PXRF is that in LXRF the instrument uses a more sensitive detector and electronics capable of resolving the entire $x$-ray 
spectrum. This means the LXRF instrument resolves $x$-ray information for each element in the sample. In a lead analysis, the LXRF instrument will resolve multiple lead peaks. This increased sensitivity in the LXRF instrumentation results in a more sensitive analytical technique than PXRF.

With the increased $x$-ray information available from LXRF, it is possible to apply mathematical matrix correction techniques to the analysis. The fundamental parameters matrix correction technique is a method used in several paint analysis [35-37]. This technique uses basic parameters such as the mass attenuation coefficient, the angle of the incoming and outgoing radiation, and the fluorescence probability to compensate for the matrix effect of varying samples. Any correction technique has limitations and the fundamental parameters technique [13] has limitations that include: 1) poor accuracy, currently about 5\%. A satisfactory accuracy would be about 1\%. 2) Several key components (anode self-absorption, window absorption, and contamination) of the matrix correction algorithm are hard to calculate and a separate experiment is usually performed to determine these. 3) The models to date ignore multiple scatterings, which become important at high energies in low atomic number matrices where incoherent and coherent scatterings are important relative to photoelectron absorption.

Kuntz and Towns [35] performed a comparison study in which LXRF 
and FAAS were used in the determination of lead at the $600 \mathrm{ppm}$ level in 10 different commercially available paints. Samples were prepared for LXRF by making paint films of uniform thickness and measuring the thickness with a micrometer. Detection limits were calculated to be $0.2 \mathrm{ppm}$ for the $L \alpha$ line and $0.4 \mathrm{ppm}$ for the L $\beta$ line, where detection limit was defined as 3 times the approximately $4 \%$ relative standard deviation. The fundamental parameters matrix correction technique was used and matrix corrections for the 10 paint samples ranged from 9 to $40 \%$ for the L $\alpha$ line and from 5 to $34 \%$ for the $\mathrm{L} \beta$ line. Using FAAS as the reference method, the x-ray method performed satisfactorily over a broad range of lead concentrations with no systematically observable matrix correction problems.

LXRF holds promise as an analytical technique in which sample preparation may be minimized. No references were found in which lead-based paint samples were analyzed specifically for lead. Advantages of LXRF also include: 1) the ability to employ matrix correction techniques to compensate for matrix effects of varying samples, 2) relatively rapid analysis time, 3) and with the matrix correction procedure, eliminating the necessity of establishing a standardization curve for each sample [35].

Even though sample preparation is minimized with LXRF, it is not completely eliminated. Sample preparation will likely consist of the paint sample being ground to minimize sample inhomogeneity 
and then being pressed into a pellet for analysis. A second disadvantage of LXRF is that most instruments use an $\mathrm{x}$-ray tube for the excitation source. This limits the excitation energy to -50 keV maximum and the analysis will use L-rays to determine lead concentration. In this area of the $x$-ray spectrum there are a large number of $x$-ray peaks and this can confuse the analysis [13]. As an example, the lead $L \alpha^{1}$ peak is at $10.549 \mathrm{keV}$ and the arsenic $\mathrm{K} \alpha^{1}$ is at $10.543 \mathrm{keV}$ [38]. If arsenic was present in a lead-based paint sample, it could lead to an incorrect determination of the lead concentration in the paint sample. A third disadvantage of LXRF is that lighter elements in the sample matrix, with absorption energies less than the emitted lead $x-$ rays, may absorb the lead $x$-rays before they reach the detector. A lower lead level would be measured than was actually present in the sample.

3.5 Neutron Activation Analysis

Neutron activation analysis (NAA) methods are based upon the measurement of radioactivity that has been induced in samples by irradiation with neutrons. The NAA process involves the capture of a neutron by the lead nucleus to give an isotope with a mass number greater by one [23]. The lead nucleus then emits either one or two neutrons and in the process also emits a $\gamma$-ray [39].

$$
{ }^{204} \mathrm{~Pb}+\mathrm{n} \longrightarrow{ }^{205} \mathrm{~Pb} \longrightarrow{ }^{203} \mathrm{~Pb}+\gamma
$$




$$
{ }^{204} \mathrm{~Pb}+\mathrm{n} \longrightarrow{ }^{205} \mathrm{~Pb} \longrightarrow{ }^{204} \mathrm{~Pb}+\gamma
$$

For reaction 2 , the prominent product $\gamma$-ray emission energies are $0.279 \mathrm{Mev}$ and $0.401 \mathrm{Mev}$. For reaction 3, the emission energies are $0.375,0.899$, and $0.912 \mathrm{Mev}$.

The instrumentation required for NAA consists of two parts: 1) a source of neutrons and 2) a detector to count the number of $\gamma$ rays given off by the irradiated sample. There must also be sufficient shielding around the neutron source and the irradiated sample to prevent radiation exposure. The neutron source is usually from a reactor, a small radioactive decay source, or a particle accelerator [23].

Lutz [39] investigated the use of NAA with a Californium-252 source in detection of lead in paint. Using ground, lead-based paint samples, he reported a yield of approximately 7 counts of the ${ }^{204 \mathrm{~m}} \mathrm{~Pb}$ isotope per milligram of lead after 2 hours of irradiation by a $600 \mathrm{\mu g}{ }^{252} \mathrm{Cf}$ source, followed by 100 minutes of counting with a $60-\mathrm{cm}^{3} \mathrm{Ge}(\mathrm{Li})$ detector. For a paint sample weighing 1.5 grams, the limit of detection for lead would be of the order of $1 \%$.

As a purely instrumental technique NAA has several advantages. NAA has the capability to use solid samples. The sample must be ground and placed in scintillation vials, but the sample does not require lengthy chemical treatment to be put into solution. It 
is also possible that the NAA analysis could be automated. The instrumentation is relatively simple and the detector elements are solid-state electronics.

NAA also has several severe disadvantages. It utilizes a radiation source that must be shielded and monitored. The detection limit is based upon the irradiation time and the counting time. To improve upon the detection limit requires longer irradiation and counting. If a radioisotope is used as the neutron source, the neutron flux will decrease with time. As an example, ${ }^{252} \mathrm{Cf}$ has a half-life of 2.55 years and in that time the neutron flux decreases by half [40].

\subsection{Mass Spectrometry}

Mass spectrometry is an analytical technique in which samples are converted to a gaseous phase, ionized and then separated based upon the mass-to-charge ratios [23]. It is possible using mass spectrometry to differentiate between the isotopes of lead and to use this difference to determine lead sources. No references were found using mass spectrometry in lead-based paint analysis, but Rabinowitz [41] used mass spectrometry to determine sources of child lead poisoning. Mass spectrometry is an extremely sensitive analytical technique, but it is complicated and costly to perform routine analysis. 


\subsection{Ion Selective Electrodes}

Ion selective electrodes (ISE) for determining lead concentrations in solution are commercially available. No references were found concerning the use of ISE in quantifying lead in lead-based paint. ISE's usually use a membrane which increase their sensitivity and selectivity to certain cations and anions [23]. Typically, ISE's suffer from interference from other elements and lead specific ISE's seem to suffer interference problems with sulphates in the presence of oxidizing agents [42]. An analysis technique using a lead ISE would require that the sample be in solution. The method used to dissolve the sample may cause severe interferences with the lead ISE. If these problems can be overcome, an ISE technique could be relatively cheap and useful.

\section{CONCLUSIONS}

There are many different potential techniques for lead-based paint analysis, but all of these have limitations. For a fieldtest method, a portable x-ray fluorescence instrument is the method of choice. Based on the literature for lead specific instruments, it is unlikely, that commercially available instruments will be capable of measuring lead at the $600 \mathrm{ppm}$ level. If the lead limits are set to $600 \mathrm{ppm}$, a laboratory 
method would be required for the analysis. The major differences among the laboratory techniques are whether the sample will be analyzed in solution or as a solid. If the lead-based paint sample will be put into solution, the method of choice will be flame atomic absorption spectroscopy. There are many standard techniques for lead analysis in paint using FAAS and the method is fast and relatively cheap. If the sample is to be analyzed as a solid, the analyst will have to develop an analytical technique for lead-based paint. Potentially, LXRF may be the most feasible method for measuring (as a solid sample) lead in dried paint films. 
1. Federal Register, 53, No. 108, June 6, 1988, 20791

2. Federal Register, 42, No. 179, Sept. 1, 1977, 44192

3. G. R. Laurer, T. J. Kneip, M. Eisenbud, R. E. Albert, N. Nelson, "New York City Health Research Council X-Ray Fluorescence Analyzer for Lead", Isotopes and Radiation Technology, 9(3), 1972, 275-277.

4. G. R. Laurer, T. J. Kneip, R. E. Albert, F. S. Kent, "X-Ray Fluorescence: Detection of Lead in Wall Paint", Science, $172(3982), 1971,466-468$.

5. J. L. Campbell, L. A. Crosse, "Portable Instrumentation for the Determination of Lead in Painted Surfaces", Bulletin of Environmental Contamination and Toxicology, 16(4), 1976, $469-473$.

6. D. Barltrop, C. L. Harford, N. J. P. Killala, "The Determination of Lead in Paint Films with a Portable Isotope Fluorescence Analyzer", Bulletin of Environmental Contamination and Toxicology, 6(6), 1971, 502-508.

7. S. D. Rasberry, "Investigation of Portable X-Ray Fluorescence Analyzers for Determining Lead on Paints Surfaces", Applied Spectroscopy, 27(2), 1973, 102-108.

8. J. C. Spurgeon, "Response Characteristics of a Portable XRay Fluorescence Lead Detector: Detection of Lead in Paint", NBSIR 73-231, June 1973, National Institute of Standards and Technology (formerly The National Bureau of Standards), Gaithersburg, MD 20899.

9. A. P. Cramp, H. W. Berger, "Evaluation of New Portable X-Ray Fluorescent Lead Analyzers for Measuring Lead in Paint", NBSIR 78-1466, May 1978, National Institute of Standards and Technology (formerly The National Bureau of Standards), Gaithersburg, MD 20899.

10. G. R. Laurer, T. J. Kneip, R. E. Albert, F. S. Kent, "Insitu Determination of Lead on Painted Surfaces for the Prevention of Childhood Lead Poisoning", Applications of Low Energy $X$ and Gamma Rays, C.A. Ziegler, ed., Gordon and Breach, New York, NY, 1971, 289-301. 
11. R. I. Bornschein, P. A. Succop, K. M. Krafft, C. S.clark, B. Peace, B. Hammond, "Exterior Surface Dust Lead, Interior House Dust Lead and Childhood Lead Exposure in an Urban Environment", Trace Subst. Environ. Health, 20, 1986, 322332 .

12. E. H. Kaplan, M. D. Lilley, R. F. Schaefer, B. Cade, A. Aesai, A. Pavda, H. G. Orbach, "Portable X-Ray Fluorescence Instruments for the Analysis of Lead in Paints", Public Health Reports, 90, 1975, 223-230.

13. R. Jenkins, R. W. Gould, D. Geddcke, Quantitative X-Ray Spectrometry, Marcel Dekker, 270 Madison Ave, New York, NY, 1981.

14. OSHA Safety and Health standards, 29CFR1910, OSHA 2206 , Sec. 96 , U.S. Dept. of Labor, Occup. Safety and Health Admin, Washington, DC.

15. W. S. Lewis, C. D. Papanicolopoulos, 0. Thompson, "Identification of Lead Based Paint: A Summary of Techniques", Lead Based Paint: Identification and control, Bethesda MD, October 27-29, 1987, 1-17, Publisher: Environmental Health and Safety Division, Georgia Institute of Technology, Atlanta, GA.

16. I. A. Currie, "Detection: Overview of Historical, Societal, and Technical Issues", Detection in Analytical Chemistry, ACS Symposium Series 361, L. A. Currie, ed., American Chemical society, Washington, DC 1988, 5-25.

17. I. A. Currie, "Dimensions of Detection in Chemical Analysis," in Trace Residue Analysis: Chemometric Estimations of Amount Uncertainty and Error, ASC Symposium Series 284, D.A. Kurtz, ed., American Chemical Society, Washington, DC, 1985, 49-81.

18. M. E. Mcknight, W. E. Byrd, "Screening Procedures for Detecting Lead in Existing Paint Films", NISTIR 89-0449, January 1989, National Institute of Standards and Technology, Gaithersburg, MD 20899.

19. J.W. Sayre, D. J. Wilson, "A spot Test for Detection of Lead in Paint", Pediatrics, 46, 1970, 783-785.

20. F. Fiegl, V. Anger, spot Tests in Inorganic Analysis, Elsevier, 52 Vanderbilt Avenue, New York, NY, 1972, 282-287.

21. "Standard Test Method for Detection of Lead in Paint and Dried Paint films", ASTM D 3618-85a, Annual Book of ASTM Standards, 6.01, American Society for Testing and Materials, Philadelphia, PA, 19103, 1988, 567-569. 
22. The Merck Index, Tenth Edition, Merck and Co., Inc, Rahway, NJ, 1983 .

23. D. A. Skoog, Principles of Instrumental Analysis, Third Edition, CBS College Publishing, 383 Madison Ave., New York, NY, 1985 .

24. K. A. Hausknecht, E. A. Ryan, L. P. Leonard, "Determination of Lead in Paint Chips Using a Modified Ashing Procedure and Atomic Absorption Spectrophotometry", Atomic Spectroscopy $3(2), 1982,53-55$.

25. "Standard Test Method for Low Concentrations of Lead, Cadmium, and cobalt in Paint by Atomic Absorption spectroscopy", ASTM D 3335-85a, Annual Book of ASTM Standards, 6.01, American Society for Testing and Materials, Philadelphia, PA, 19103, 1988, 507-509.

26. M. Kubota, D. W. Golightly, R. Mavrodineanu, "A Rapid Wireloop Method for Determination of Lead in Paint by Atomic Absorption Spectrometry", Applied Spectroscopy, 30(1), 1976, 56-63.

27. R. Reeves, T. Kjellstroem, M. Dallow, P. Mullins, "Analysis of Lead in Blood, Paint, Soil, and House Dust for the Assessment of Human Lead Exposure in Auckland (N.Z.) ", New Zealand Journal of Science, 25, 1982, 221-227.

28. A. Steenhout, S. Vandenbreede, "Old Paints in Brussels Houses: a New Look on an Unexplored Lead Source", Heavy Metals in the Environment, $5^{\text {th }}$ Int Conf., 2, 1985, 573-574

29. W. T. Sturges, R. M. Harrison, "An Assessment of the Contribution from Paint Flakes to the Lead content of some Street and Household Dusts", Science of the Total Environment, 44(3), 1985, 225-234.

30. W. K. Porter, Jr, "Collaborative study of the Determination of Lead in Alkyd and Latex Paints", Journal of the AOAC, $57(3), 1974,614-617$.

31. Bock, R., A Handbook of Decomposition Methods in Analytical Chemistry, John Wiley and Sons, 605 Third Avenue, New York, NY, 1979, 146-147.

32. Interlaboratory Test Data for D 3335, Test for Low concentrations of Lead and Cadmium in Paint by Atomic Absorption Spectroscopy, ASTM Research Report, D-1-1005, Feb. 2, 1977, American Society for Testing and Materials, Philadelphia, PA, 19103. 
33. Analytical Methods for Atomic Absorption Spectrophotometry, The Perkin-Elmer Corp., Norwalk, CT, 1971.

34. P. C. Lai, K. W. Fung, "Determination of Lead in Paint by Differential-Pulse Anodic-Stripping Voltammetry", Analyst, $103,1978,1244-1248$.

35. G. S. Kuntz, R. L. R. Towns, "Determination of Lead in Paint by Energy Dispersive X-Ray Fluorescence Spectrometry", Journal of Coatings Technology, 54(687), 1982, 63-69.

36. L. H. Christensen, I. Drabek, "A Generalized Matrix Correction Approach for Energy-Dispersive X-Ray Fluorescence Analysis of Paint Using Fundamental Parameters and Scattered Silver K $\alpha$ Peaks", Advances in X-Ray Analysis, 26, 1983, 377384 .

37. L. H. Christensen, I. Drabek, "Energy-Dispersive X-Ray Fluorescence Spectrometry: a Versatile Analytical Technique for Determination of Major Elements in Paint", Congr. FATIPEC, 1984, 17th(1), 327-345.

38. H. A. Liebhafsky, H. G. Pfeiffer, E. H. Winslow, P. D. Zemany, X-Rays, Electrons, and Analytical Chemistry: Spectrochemical Analys is with $\mathrm{X}$-Rays, John Wiley and Sons, 605 Third Avenue, New York, NY, 1972.

39. G. J. Lutz, "Determination of Lead in Paint with Fast Neutrons from a Californium-252 Source", Analytical Chemistry, 46, 1974, 618-620.

40. Handbook of Chemistry and Physics, $49^{\text {th }}$ Edition, The Chemical Rubber Company, 18901 Cranwood Parkway, Cleveland, $\mathrm{OH}, 1968, \mathrm{~B}-91$.

41. M. B. Rabinowitz, "Stable Isotope Mass Spectrometry in Childhood Lead Poisoning", Biological Trace Element Research, 12, 1987, 223-229.

42. A. M. Y. Jaber, G. J. Moody, J. D. R. Thomas, "Studies on Lead Ion-Selective Electrodes Based on Polyalkoxylates", Analyst, 9(113), 1988, 1409-1413. 


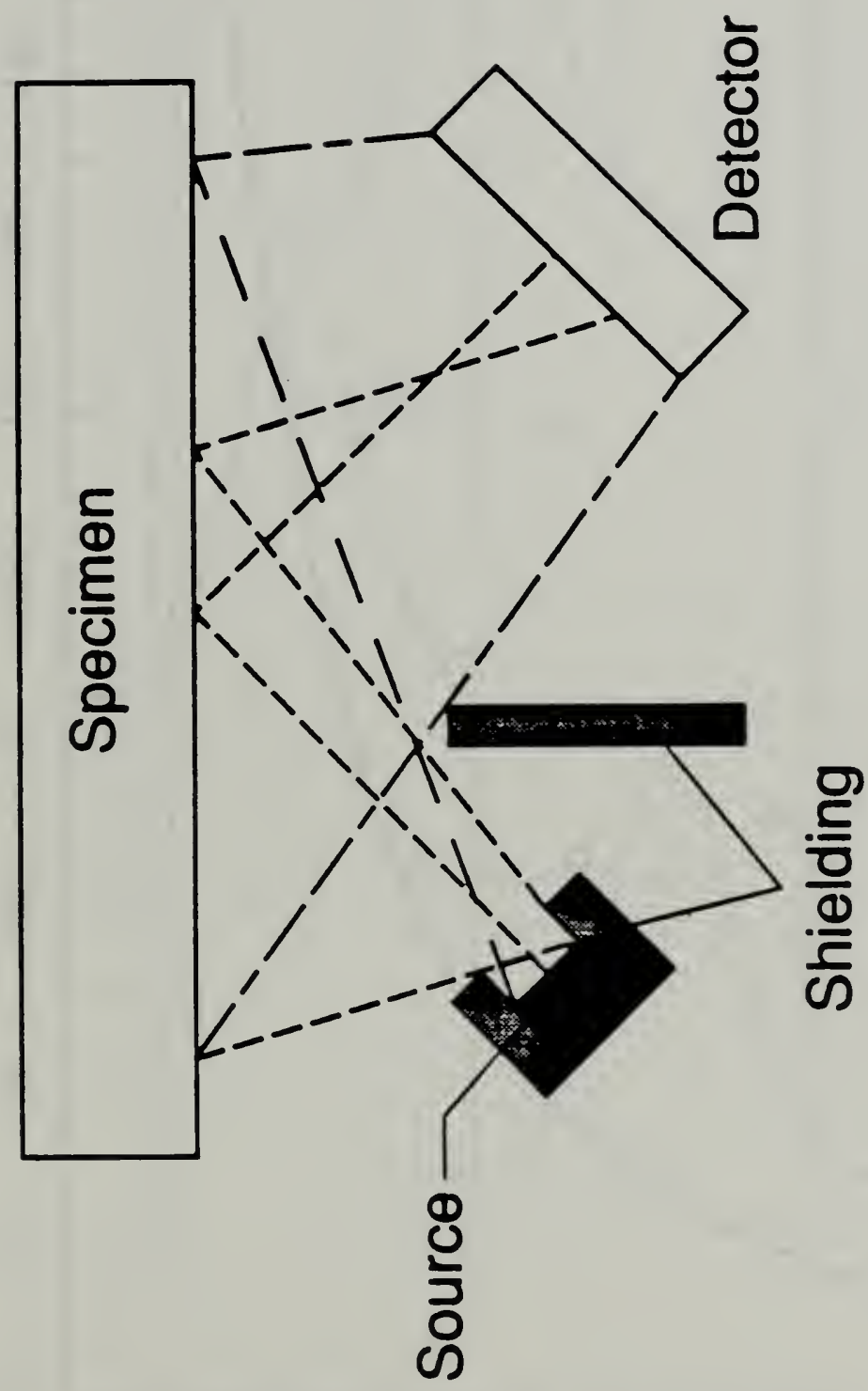

$\dot{\sim}$

央

틍

出

4)

- $\frac{x}{x}$

$+$

(1)

E -1

ว

$+$

¿

$0 \dot{1}$

0 거

ฮै

o

o

पू

30

4 6

$>x$

ชั

1

$x x$

(1)

8.

䒓

4

a

ช

42

0

ธิ

임

궁

\%

48

วू०

जी

ㅇ․

บ

สี ว

00

.

간 3

$\dot{4}$

$\therefore$ -

(1)

나.न

วำ

以ू 


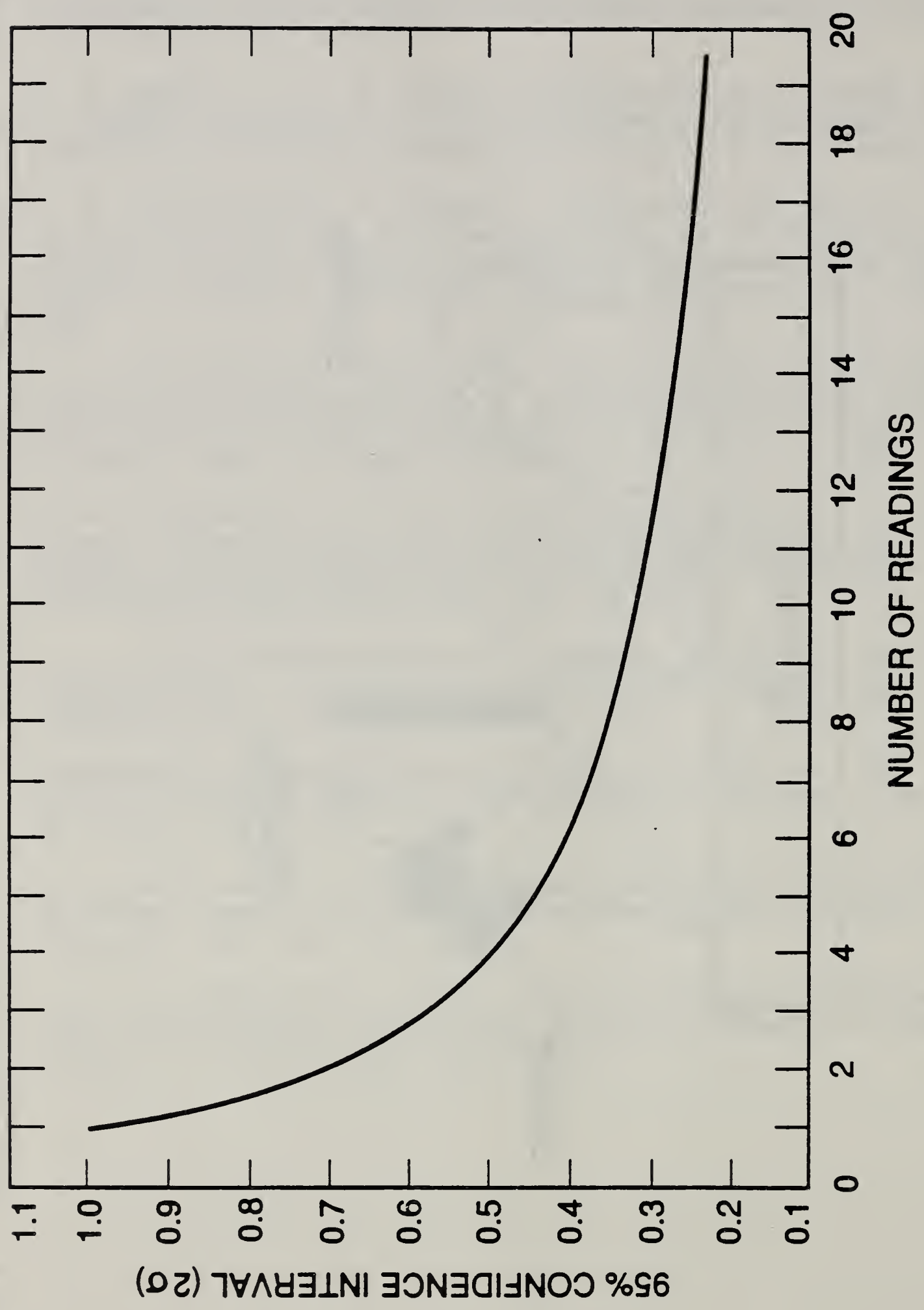




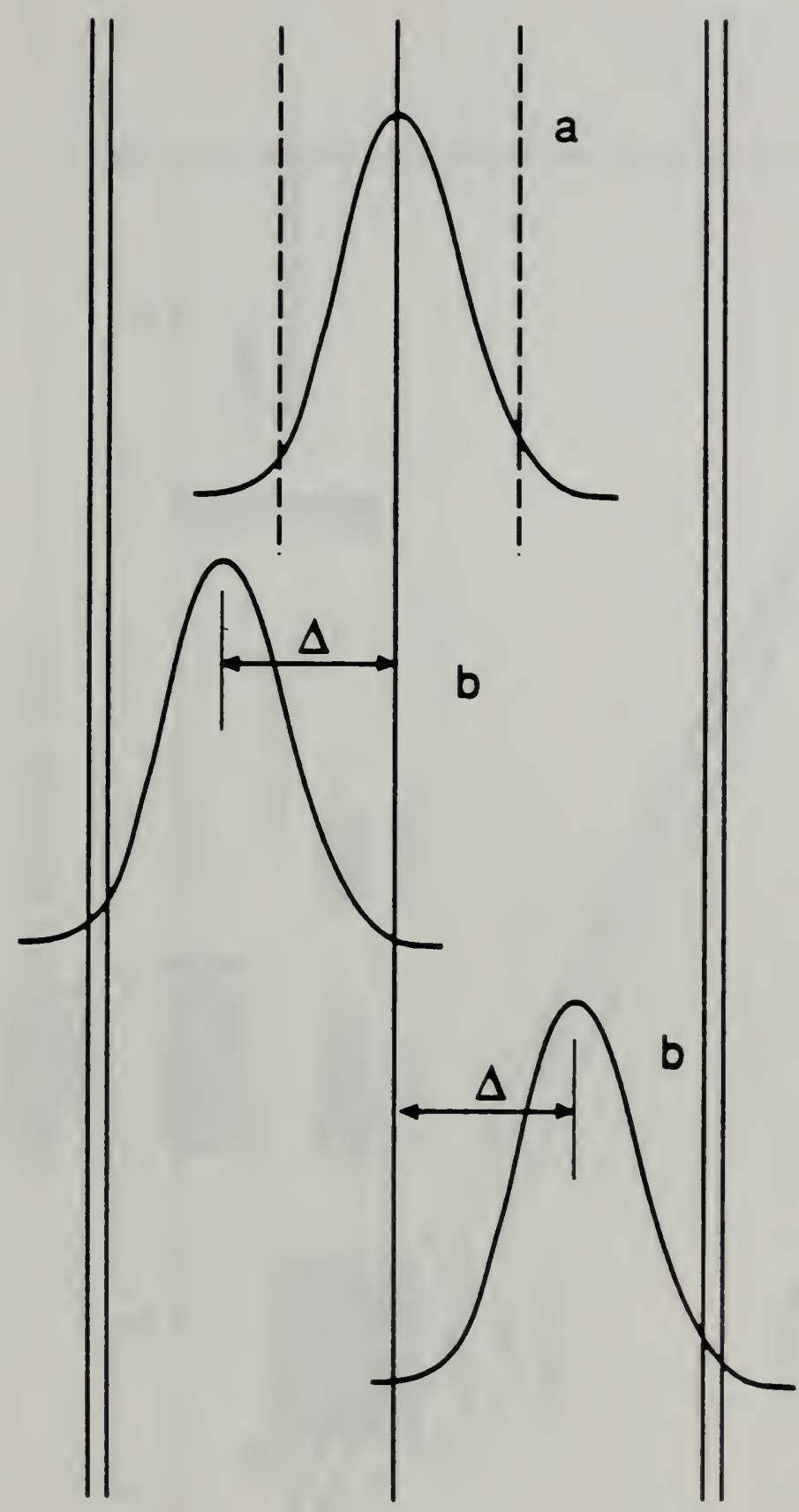

Figure 3. Hypothetical distribution of results of measurement process when a) limit for bias is zero and b) when limit for bias is $\Delta$. Solid double lines correspond to $95 \%$ confidence interval for measurement process with limit for bias of $\Delta$. Dotted lines correspond to $95 \%$ confidence interval when bias is zero. 


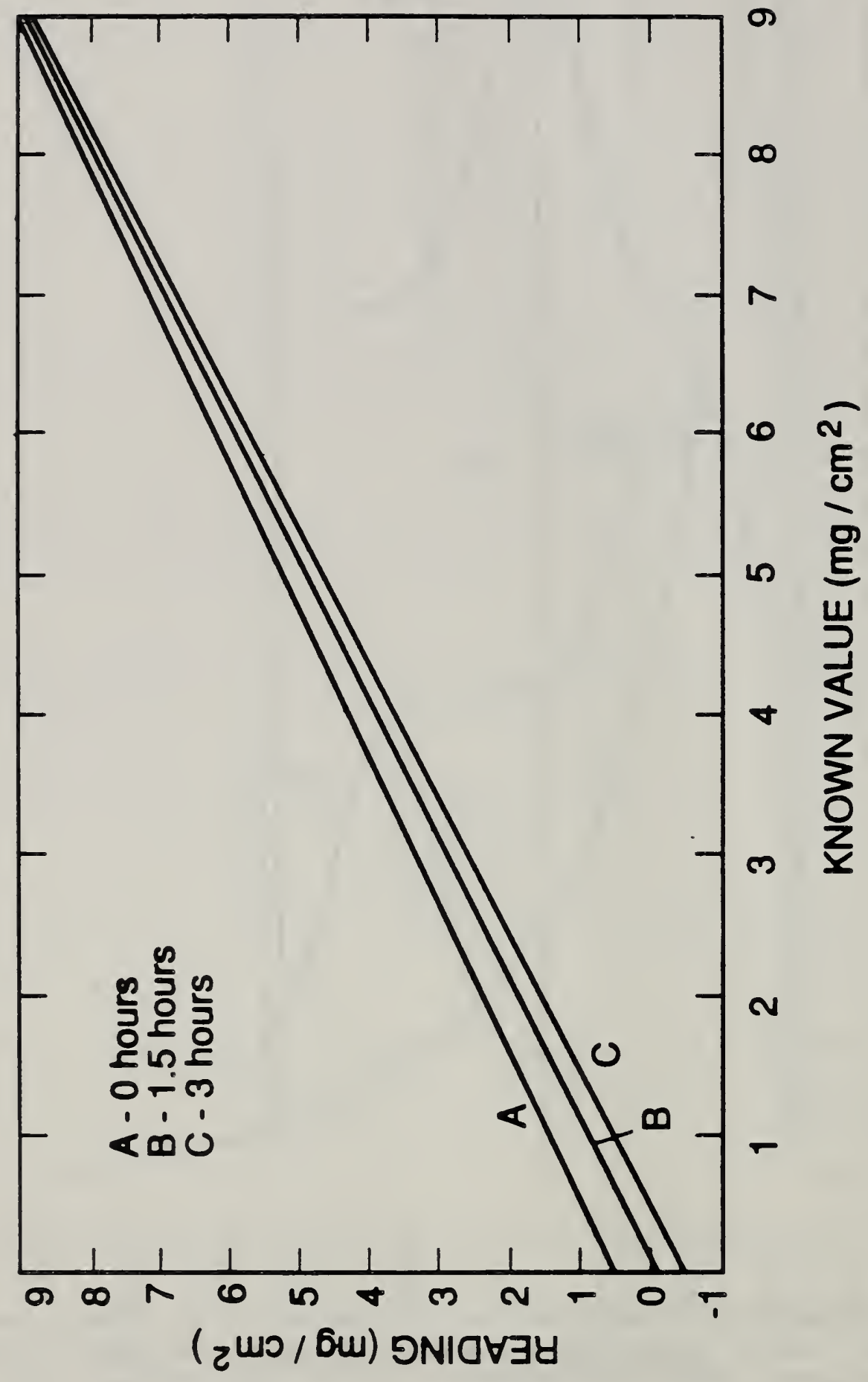

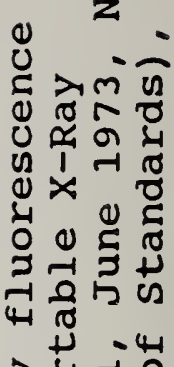

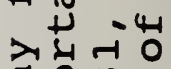
ช $\mathrm{m}$

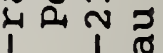
x (1)

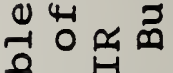
की था न +0 ठ 내그 \& $-1=+$ 先 도 0 ○ वै ह (1) म्न है 녹도 ठठ ठ त्र i 0 \% (1) थ 0 4 近 을 责 设 0 ฉ્ય ᄃ요 00 ठ ठ

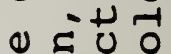
400 - -1 d न का 过 ते .. (1) ज्ञ +0 .

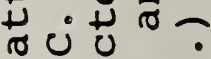
\& य แ口㟔望文 हี ำ ฮ 0 出出芯范 प्ञ 0 फ 일 - Е - बिए ज ह 政 \& 4 म्र 牙药落

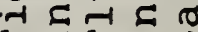

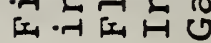



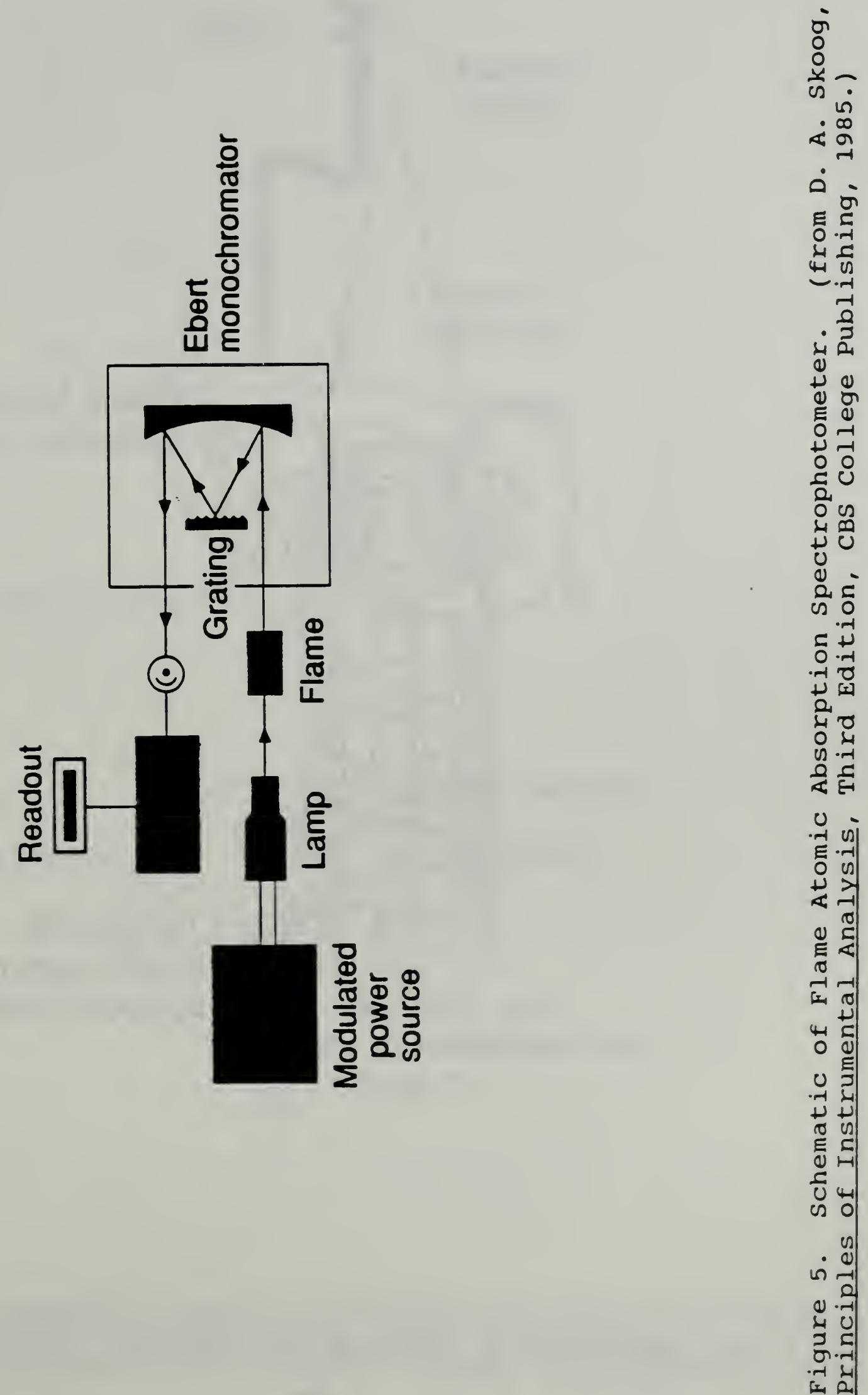


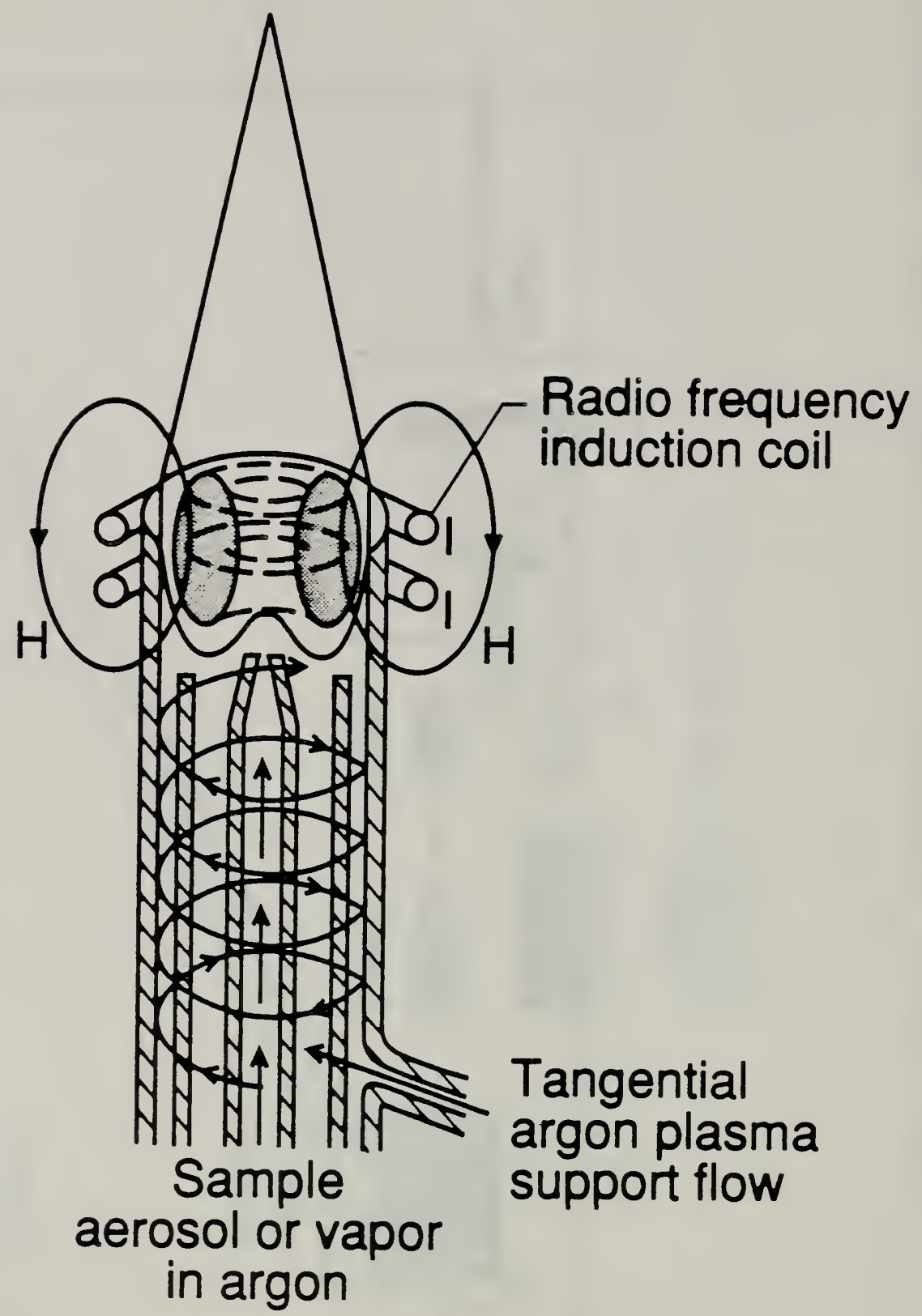

Figure 6. Inductively Coupled Plasma source diagram. (from D. A. Skoog, principles of Instrumental Analysis, Third Edition, CBS College Publishing, 1985.) 

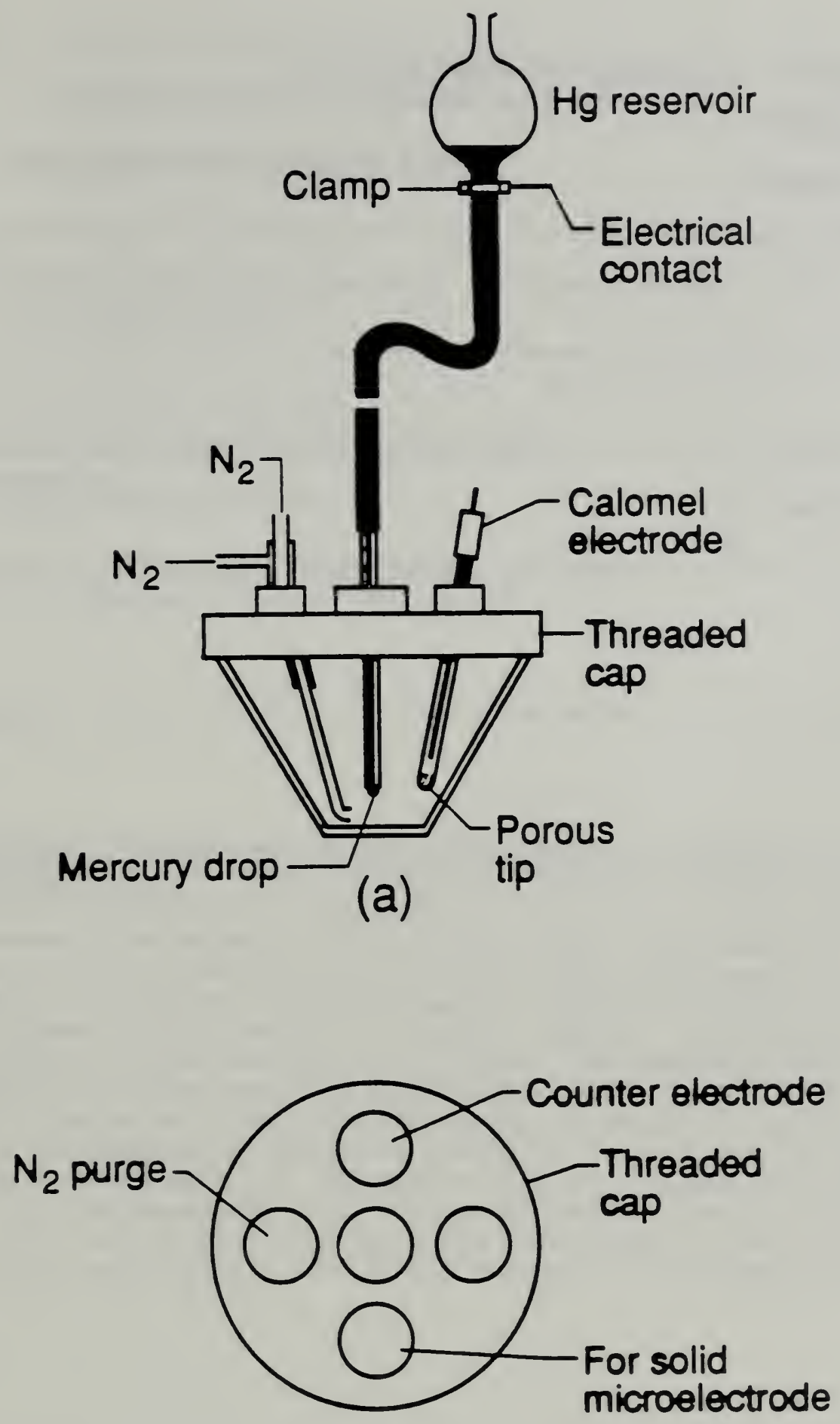

(b)

Figure 7. A schematic diagram of the polarographic technique a) Side view b) top view. (from D. A. Skoog, principles of Instrumental Analysis, Third Edition, CBS College Publishing, 1985.) 



\begin{tabular}{|c|c|c|}
\hline \multirow{4}{*}{$\begin{array}{l}\text { NIST-114A } \\
\text { (REV. 3-89) }\end{array}$} & \multirow{4}{*}{$\begin{array}{l}\text { U.S. DEPARTMENT OF COMMERCE } \\
\text { NATIONAL INSTITUTE OF STANDARDS AND TECHNOLOGY } \\
\text { BIBLIOGRAPHIC DATA SHEET }\end{array}$} & 1. PUEUCATION OR REPOAT NUMBER \\
\hline & & NISTIR 89-4205 \\
\hline & & \\
\hline & & $\begin{array}{l}\text { PUEUCATIONOATE } \\
\text { January } 1990\end{array}$ \\
\hline
\end{tabular}

\section{TITLEANO SUBTITLE}

Porential Measurement Methods for Measuring and Detecting Lead in Existing

Paint Films: A Iiterature Review

5. AUTHOR(S)

W. Eric Byrd, and Mary E. McKright

6. PERFORMINO ORQANIZATION (IF JOINT OR OTHER THAN NIST, SEE INSTRUCTIONS)

U.S. DEPAATMEMT OF COMMERCE

MATIOMAL INSTITUTE OF STANDAROS ANO TECHNOLOGY

GATHERSBURQ, MO 20899

7. CONTRACT/GRANT MUMBER

8. TYPE OF REPORT ANO PERIOD COVERED

9. SPONSORIMQ ORQANIZATION NAME ANO COMPLETE ADORESS (STREET, CITY, STATE, ZMF)

U.S. Department of Eousing and Urban Development

10. SUPPLEMENTARY NOTES

DOCUMENT DESCRIBES A COMPUTER PROGRAM; SF-185, FIPS SOFTWARE SUMMARY, IS ATTACMEO.

11. 28STRACT (A 2OO-WORO OR LESS FACTUAL SUMMARY OF MOST SIOMIFICANT INFORMATION. IF DOCUMEMT INCLUDES A SIGNIFICANT BIBUOGRAPHY OR UTERATURE SURVEY, MENTION IT HERE.)

Recent legislation required the U.S. Department of Housing and Urban Developaent (HUD) co establish procedures to eliminare, as Ear as practicable, the hazards of lead-based paint poisoning il any existing HUD-controlled housing. Thus, HUD promulgared a regularion inicin requires abatement to eliminate lead-based paint poisoning hazards in housing in inich the concentration of lead in paint equals or exceeds $1 \mathrm{mg} / \mathrm{cm}^{2}$. The legislation also zequired $\because$ ito to review rest aethods for neasuring lead in paint. The National Instifure of standards anc Technology (NIST) was tasked with this requirement. That review is the subject of this zepor Iest =ethods were evaluated based on the following criteria: 1) sajery, 2) reliabiliz 3) accuracy, 4) precision, 5) detection limit, 6) ease of use, and 7) (achnical skili reçuired to nake a zeasurement, 8) nondestructive, and 9) cost of an analysis. Methods were separared into two caregories: 1) Eield test aethods and 2) laborarory rest zethocis. The laboratory test aethods were also separated by whether the sample needed to be in solution or could be analyzed as a solid. None of the potential test vethods aet all oz the desired crizeria.

12 KEY WOROS (6 TO 12 ENTRIES; ALPHABETICAL OROER; CAPITALIE ONLY PROPER NAMES; ANO SEPARATE KEY WOROS IY SEMICOLONS) analjsis; lead; literature review; paint; x-ray Eluorescence; Elame aromic absorption; spor rest; inductively coupled plasma; neutron activation analysis; voltametry; aass specromerzy; ion selective electrodes.

\begin{tabular}{|c|c|c|}
\hline 13. AVA & ABIUT & 14. NUMBER OF PRINTED PAGES \\
\hline$\ddot{\pi}$ & $\begin{array}{l}\text { UNUMITED } \\
\text { FOR OFFICIAL OISTRIBUTION. DO NOT RELEASE TO NATIONAL TECHMICAL INFORMATION SERVICE (NTIS). }\end{array}$ & -5 \\
\hline$\because$ & $\begin{array}{l}\text { OROER FRON SUPERINTENOENT OF DOCUMENTS. U.S. GOVERNMENT PRINTING OFFICE, } \\
\text { WASHINOTON, DC } 20402 \text {. } \\
\text { OROER FROM NATIONAL TECHNICAL INFORMATION SERVICE (NTIS), SPRINOFIEL. VA Z2161. }\end{array}$ & 15. PRICE \\
\hline
\end{tabular}




